\title{
Implementation of a Smart Battery Charger Using LLC Resonant Converter
}

\author{
Nwosu, E.U., Olalere, N.A., Shopade, G.N., Ogbodo, J.I. and Jumah, A.A.
}

\begin{abstract}
This research was influenced by the need to eradicate voltage selection error in manual battery-charging, as well as the necessity for getting more batteries charged within a short duration without compromising the cycle life of a battery. Minimizing human interference in charging of batteries as a means of making the process stress-free, safer and faster is also a motivation for this work. This paper presents a battery charger which takes accurate decisions by itself and eliminates poor charging parameters which can damage even brand new batteries. The battery charging unit automatically senses the battery terminal voltage(s), supplies appropriate charging voltage/current, and terminates charging process based on preset operational conditions of voltage, current and temperature. Key components of the developed prototype include PIC16F877A microcontroller chip, LLC resonant converter, and an LCD based display unit. The chip runs dedicated codes that control all tasks involved in the operation of the charger. Pulse-width modulation (PWM) technique was employed to control switching duty cycle which consequently varies the output of the converter and enables battery-charging from 6 -volt to 48-volt. Before embarking on the actual constructions, simulations were done to evaluate the performance of the system. The model was subjected to tests under various load conditions and the results agreed with objectives of the research.
\end{abstract}

Keywords: LLC Resonant Converter, Duty Cycle, PWM Technique, Cycle Life.

\section{Introduction}

The daily period of a power outage is usually more than the hours for which power is available in many developing countries [1]. Thus, people in such environment try to store electrical energy as much as they could within the short duration for which the public power supply is available. They make use of rechargeable batteries to store energy and retrieve it later through the use of inverters; since AC mains is often required to power many of the loads [2]. To recharge a battery, an inevitable requirement is a

Nwosu, E.U. (Department of Industrial Maintenance Engineering, Yaba College of Technology, Department of Physics, Federal University of Technology, Akure.

Olalere, N.A., Shopade, G.N. and Ogbodo, J.I. (Department of Industrial Maintenance Engineering, Yaba College of Technology)

Jumah, A.A. (Department of Mechatronics Engineering, Yaba College of Technology)

Corresponding author: nurudeen.olalere@yabatech.edu.ng

Telephone Number: +234-805-848-4851 battery charger. This equipment is not just intended to replenish rechargeable batteries but also to preserve the battery life[3]. Inappropriate charging voltage/current is a major cause of reduced cycle life and diminishing rate of charge acceptance in rechargeable batteries [4].

The consequences of exposing a battery to an excessively higher voltage while charging can be catastrophic in some cases. Similarly, charging a battery under an extremely lower voltage can weaken it [5]. The reliability and durability of rechargeable batteries depend largely on the performance and capability of the charging methodology employed [6].

There are numerous types of battery chargers but they all operate on similar basic principles which involves the provision of a regulated, fixed or adjustable DC voltage usually from a rectified AC supply or from another DC source like the photovoltaic cells. A typical charger steps down the 
voltage at its input with a corresponding stepping up of current at its output [7].

A variety of battery charging methods are in existence. These include the constantcurrent, constant-voltage, constant-current constant-voltage, and the constant-trickle charging. Fast-charge ability is one of the features that actually make a particular charging system different and better in performance than another [8]. The purpose of fast charging is to put in as much energy as it takes to bring a battery back to fully charged state within the shortest possible time without permanently affecting the long term performance of the battery or causing any damage to it. Properly executed fastcharge, matched with the specifications of the battery rated for such charging, will deliver a long cycle life [9]. Charge termination is also a distinctive property of some battery chargers which cannot be disregarded [10]. When a battery is yet to be fully charged, the electrical energy of the charge current is transformed into chemical energy in the cells by the charging reactions. However, when all of the available active materials have been transformed into stored charged, the energy present in the charging current then activates other unwanted chemical reactions, producing heat and gases from the cells [4]. In a fast-charging system, the high charging rate involved causes rapid electrochemical reactions within the cells of the battery. Consequently, whenever the battery goes into overcharge (continued charging of a battery after it has become fully charged), these reactions lead to a swift increase in temperature and pressure of the internal cells. The resultant effect is battery damage [11]. Although, flooded lead-acid batteries do emit corrosive and explosive gases while experiencing overcharge but to avert this impairment, when a battery approaches full charge, the charging current is often reduced to a lower (top-off) level. Thus, charge termination is a unit of a fast-charge system for preventing the high-rate overcharge. The reliability of many chargers depends on the method of charge termination put in place. [12]. Voltage-based and temperature-based charge termination methods are the two common practical approaches.

Using a switch mode power supply (SMPS) in the implementation of a smart battery charger is majorly to improve the efficiency of the charger by reducing the energy losses associated with the conventional power conversion method [13]. The LLC resonant converter used in this research is essentially one of the numerous variants of DC-DC converters in existence. The choice of this particular topology is anchored on its reduced switching losses despite the high switching frequency involved. Consequently, a portable, lightweight, and high power density battery charger were realized.

\section{Materials and Methods}

The smart battery charger automatically senses battery terminal voltage within the range of 6-volt to 48-volt, supply the predetermined charging voltage, and terminate the charging process when a combination of voltage, current and temperature indicate that the battery is fully charged. For effective charge termination, the system monitors battery voltage and current via designated sensing circuits. The charger is not only intended to prevent overcharge but also undercharge conditions. This was achieved by indirectly monitoring the output dc voltage with a microcontroller. While the charging voltage is controlled through pulse width modulation (PWM) technique, the charging current depends on the state of discharge 
(SOD) of the battery as well as its capacity. Although, the maximum current a battery charger can deliver is generally based on its rating. This parameter determines the capacity of battery the system can effectively charge within the shortest allowed duration.

The developed model which has both hardware and software components contains mainly a PIC16F877A microcontroller, an LLC resonant converter, a $16 \times 2$ LCD unit and various circuits divided into modules. These include the rectifier, regulator, sensors, and MOSFET gate drive unit. The LCD module was integrated into the system for displaying some essential parameters such as the initial battery voltage as well as the charging current and voltage at any instant. Also displayed by the LCD unit is the temperature of the battery under charge and the instantaneous battery voltage as charging progresses. The microcontroller chip runs dedicated codes that control all the tasks involved in the operation of the system including the data displayed by the LCD module.

Electrical energy losses usually encountered in the process of power conversion due to usage of the conventional iron-core transformer was avoided by introducing a high frequency ferrite-core transformer. This device forms part of the LLC resonant converter which is fundamentally a type of SMPS. Essential components of the system were interfaced with the PIC microcontroller to establish required communication among them. Before embarking on the physical construction, computer simulations were carried out to evaluate the performance of the system and make the required alterations.

\section{A System Overview}

The battery charger is powered via 230 -volt, 50-hertz ac supply. Simply by connecting its power cord to any ac mains outlet, the line rectifier produces a high dc voltage of minimal ripple content. This unregulated voltage is fed to the LLC resonant converter and a 7805 voltage regulator. The resonant converter supplies an adjustable constant $\mathrm{dc}$ voltage to the battery (or pack of batteries) at its output. The specific charging voltage to be made available at any instant is determined by the microcontroller which has been programmed to enable a maximum charging voltage of 9-volt for a 6 -volt battery, 15-volt for a 12-volt battery, 30-volt for a 24-volt battery pack, 45-volt for a 36volt battery pack and 60-volt for a 48-volt battery pack. However, the magnitude of the charging voltage which is always constant at any instant depends on the terminal voltage of the battery to be charged sensed by the microcontroller via the sensor. A command to terminate the charging process at any moment is given by the microcontroller based on information available from the sensors. The 7805 voltage regulator produces a 5-volt regulated dc voltage to energize the microcontroller circuitry. The LCD helps to know the status of the battery under-charge as well as performance parameters of the charger itself.

\section{B Components Used}

Selection of component was based on definite considerations. To allow minimal divergence between the simulation and experimental test results, the components used were either the same or have similar properties as those used in the simulation. Where applicable, the physical components were subjected to appropriate tests prior to usage 


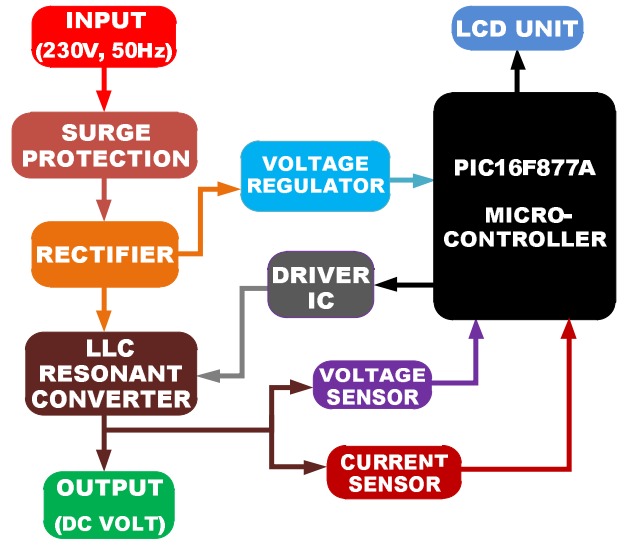

Figure. 1: Block Diagram of the Battery Charger

\section{i. The Microcontroller Chip}

This is the control unit that can be termed as the heart of the entire system. PIC16F877A microcontroller is a four-port, 40 pin PDIP (Plastic Dual Inline Package) used in the prototype. Thirty-three of its pins are available for input and output. Each of the pins can be used for both input (read data from devices) and output (send instruction to devices) as they are bidirectional. The microcontroller is also used for generating the PWM signal which is handled by its two CCP (capture compare PWM) modules. Its ability to generate variable duty cycle digital signals is of great benefit in this research. The duty cycles for corresponding output dc voltages from the resonant converter were spelt out in the $\mathrm{C}$ program. Duty cycle of the signals generated by the microcontroller at any instant is determined by the output of the sensors. PIC16F877A microcontroller was chosen also because of its flash memory's multiple write-erase feature, support for up to eight analogue sensors, low cost and ease of handling. Programming of this controller was done in $\mathrm{C}$ language.

\section{ii. The Voltage Sensing Unit}

For the battery charger to automatically supply the appropriate charging voltage at any instant, the microcontroller has to determine the state-of-charge (SoC) of the connected battery. In the set of instructions given to the microcontroller, the $\mathrm{SoC}$ is expressed in percentage considering the minimum and maximum terminal voltage from 6volt battery to 48volts battery pack. For a typical 12volt lead-acid battery, the SoC is considered as $100 \%$ at a battery terminal voltage of $14.5 \mathrm{volt}$ and $0 \%$ at a terminal voltage of 11.5 volt since the battery is not designed to be discharged below this voltage level. Exposing the microcontroller directly to this magnitude of voltage is unacceptable. Thus, a battery voltage sensing unit is required to scale down the terminal voltage to a value (maximum of 5 Volt) compatible with the microcontroller. The stepped down analogue voltage signal: $\mathrm{V}_{\text {BAT_}}$ SENSE, (as shown in figure 2) serves as input to the ADC (Analog to Digital Converter) of the microcontroller where it gets converted into quantized values (series of bits) which the microcontroller can understand and then process to determine SoC of the connected battery. The scaled analogue input voltage is divided into 1024 quantized levels by the ADC with a value of 0 for $0 \%$ SoC and 1023 for 100\% SoC. Resistance of the potentiometer in the voltage divider is configured based on the 5volt reference voltage. C1 is a low pass filter for blocking unwanted signals from the output of the attenuator.

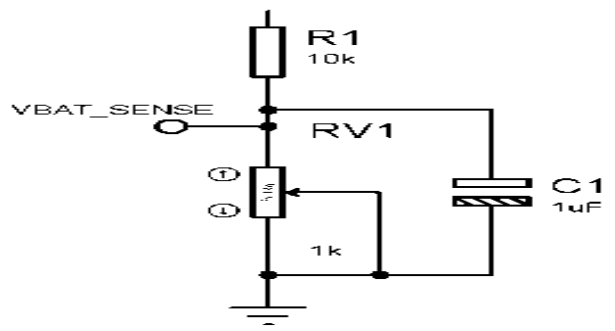

Figure. 2: Voltage Sensing Circuit

\section{iii. The Current Sensing Unit}

Generally, the duration it takes to fully recharge a battery depends on its state-of- 
discharge (SoD) and the characterized charging losses principally associated with the internal resistance of the battery. Achieving fast charging means reducing the charging time by increasing the charging current when necessary. Since the charging current can be increased by increasing the charging voltage, the current sensing unit, which consists of a current sense amplifier (CSA) and a low pass filter, measures the charging current and communicates it with the microcontroller for necessary adjustment. CSA is a specialized operational amplifier (Op-amp) that monitors current flow by measuring the voltage drop across its sensing element. Therefore sensing of the charging current, which should not be less than one-tenth of the battery capacity (Ah rating), begins by converting it to a voltage measured across a low-value sense resistor $\mathrm{R} 4$ as shown in figure 3. A low-offset Opamp (LM358) is then used to boost the ultra-low voltage before sending it to the ADC pin of the microcontroller for sampling as discussed earlier. The low-pass filter (C17) is connected across output of the Op-amp to prevent electrical noise.

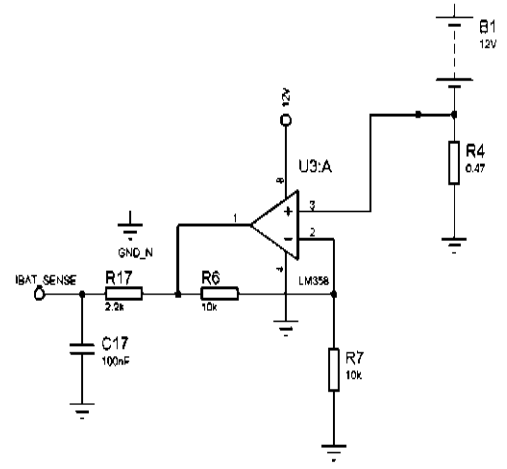

Figure. 3: Current Sensing Circuit

\section{iv. The LCD Unit}

The LCD module displays the charging voltage and current at any instant. It gives the initial battery voltage as well as the temperature of the battery as charging progresses. LM016L is a 14 pin, $16 \times 2 \mathrm{LCD}$ module utilized in the prototype. The reasons for choosing this particular type include the ease of programming it, its low power consumption, as well as its ability to display numbers, character, and graphics. The microcontroller communicates with the LCD module via its in-built HD44780 controller such that all the information to be displayed by the LCD is determined by the PIC microcontroller. The in-built controller of the module was initialized before sending data to the LCD otherwise nothing would be displayed. To power the LCD module, the VSS, VDD and VEE pins were used for power terminals.

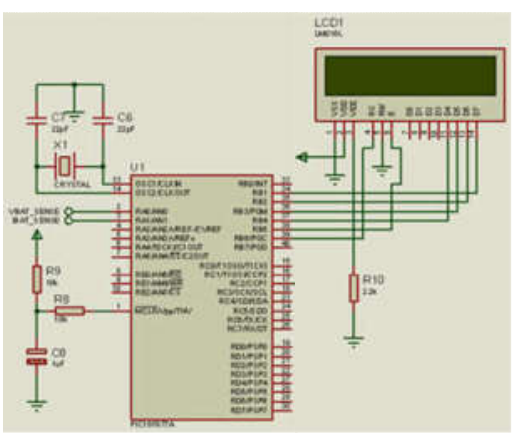

Figure 4: Interfacing PIC16F877A with the LCD

\section{v. The Line Rectifier}

This is a device generally needed to derive DC power from an AC mains. A full-wave rectifier, consisting of four number of 6A10 diode was used for this purpose. The $4700 \mu \mathrm{F}$ electrolytic capacitor connected across the output of the rectifier is an electronic filter employed to eliminate ac ripple voltage associated with the rectified dc voltage. 


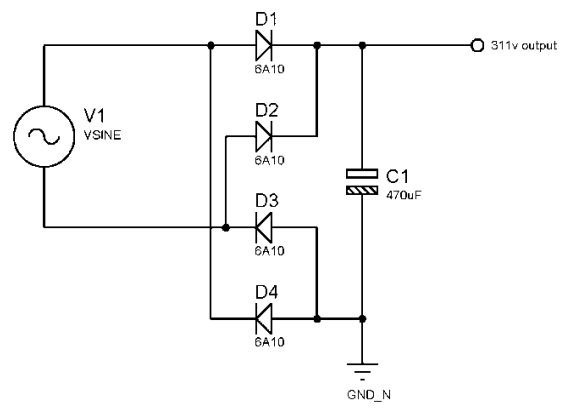

Figure 5: Full-Wave Rectifier Circuit

The full-wave rectifier was used because it produces less ripple than a half-wave rectifier which consequently requires more filtering. This silicon rectifier was selected due to some of its unique characteristics. It can conveniently handle high voltage from the mains without dissipating too much heat. It has a maximum recurrent peak reverse voltage of $1 \mathrm{kV}$, a maximum average forward output current of 6-ampere, a maximum forward voltage drop of 0.95 -volt at $1.0 \mathrm{~A}$ DC per element. This diode possesses a typical junction capacitance of 150 pico-farads.

\section{vi. The LLC Resonant Converter}

This is a resonant converter that uses two inductors and a capacitor to create a resonant circuit also known as "resonant tank" where $C_{n}, L_{n}$ and $L_{m}$ are the series resonant capacitance, the series resonant inductance, and the magnetizing inductance respectively (Fig. 3). Other parts of the converter include the $\mathrm{H}$-bridge switching network (Q1-Q4) and a full-wave rectifier $(D 1, D 8)$ both of which are isolated from each other by a high frequency transformer (TR1). The resonant tank is introduced to reduce switching losses which occur during the turn-on and turn-off intervals of the transistors.

Reducing losses improves efficiency which enables having a converter of higher power density. One of the reasons for using a resonant converter is that it allows the transistors to switch at zero voltage and/or zero current condition. The resonant tank establishes resonance at the switching frequency which enables the MOSFETs to switch at the zero-crossing points as they rather perceive a sine wave. The benefit of making the switching transistors see a sine wave is that it allows for higher switching frequency which enables a reduction in the dimensions and weights of magnetic components, filter capacitors, and the heat sink required. Consequently, the entire unit is made portable and light in weight. As the switching time is reduced at higher switching frequency, such a lower switching time lessens the sharp pulse edge transition which produces transients that generate noise and electromagnetic interference (EMI). Also, reducing the switching time decreases power consumption because power dissipation during the on-off transition is zero or minimal. Therefore, the zero-voltage switching (ZVS) and/or zerocurrent switching (ZCS) ability helps in reducing pressure on the transistors as the voltage stress is low due to the soft switching.

The LLC resonant converter has high efficiency near the resonant frequency where it operates in the continuous conduction mode (CCM). Although the implemented converter is duty-cycle controlled, it exhibits resonance at two different frequencies (on-load and off-load frequencies) expressed as:

$$
\begin{gathered}
f_{r 1}=\frac{1}{2 \pi \sqrt{L_{r} G_{r}}} \\
f_{r 2}=\frac{1}{2 \pi \sqrt{\left(L_{T}+L_{m}\right) L_{T}}}
\end{gathered}
$$

These equations represent the resonant frequency at operating mode 1 and 2 
respectively. The converter is operating at mode 1 when the transformer is driving power to the output. At this point, $L_{m}$ is cut off from the circuit. Contrarily, the converter is operating at mode 2 when the transformer stops driving power to the output. ZVS is ensured at frequencies higher than $f_{r 1}$. The resonant tank filters out higher harmonic currents such that only sinusoidal currents flow through it. Consequently, the voltage applied to the resonant tank is being lagged by the current and this permits the MOSFETs to be turned on when the voltage is near zero. For higher efficiency of the converter, both the switching and the conduction losses were minimized. Current of the $L_{m}$ being a circulating current is useful in achieving ZVS but it constitutes extra losses since it does not carry energy to the load.

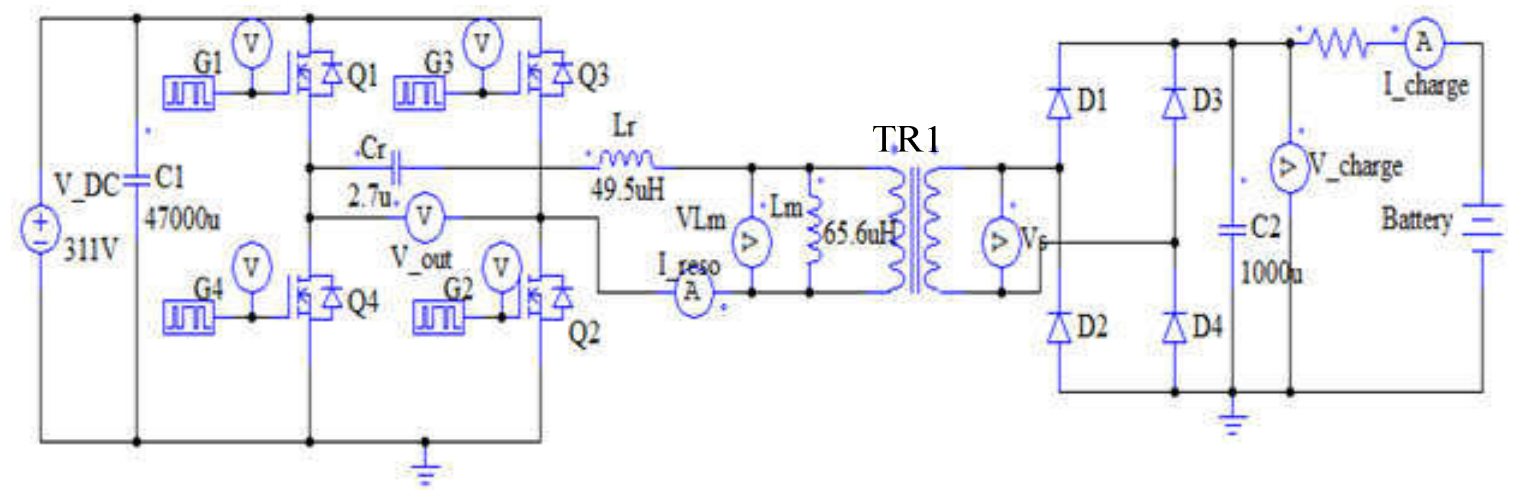

Figure 6: The LLC Full Bridge DC-DC Resonant Converter PSIM Simulation Circuit

Therefore, the total inductance value was increased to lessen the losses. Although, increasing the switching frequency could equally address this issue. $\mathrm{N}$-channel MOSFET (IRFP22N50A) is the element used for power switching operation due to its low on-state resistance which helps to minimize conduction losses, as well as its high switching frequency of up to $1 \mathrm{MHz}$. Both the high side MOSFETs $\left(Q^{1}, Q^{3}\right)$ and the low side MOSFETs $\left(Q^{2}, Q^{4}\right)$ of the switching bridge are turned on and off alternately by a PWM control square wave signal from the microcontroller via the MOSFET gate driver unit. Duty cycle of the gate drive signal at any instant depends on the battery terminal voltage (number of batteries) sensed by the voltage sensing unit. In other words, the duty cycle of the control signal determines the average DC voltage supplied by the charger at any instant. R7-
R10 are the gate drive resistors for the MOSFETs switches. Their values determine the charge and discharge times of the input parasitic capacitances of the MOSFETs, as well as the turn-on and turn-off times of the MOSFET transistors. The MOSFETs serve as controlled-switch network (inverter) for the DC-DC resonant converter. They change the DC power to an intermediate AC power. Thus, the switching bridge has distinct DC and AC sides as shown in Figure 6. The DC side is fed from the output of the line rectifier, while the output $\mathrm{AC}$ voltage is connected to the primary side of the isolation/step down transformer (TR1) via the LLC resonant tank. Excited by the square wave ac voltage generated from the switching network, the resonant tank produces sinusoidal current at resonance frequency to create a changing magnetic field in the primary windings of the 


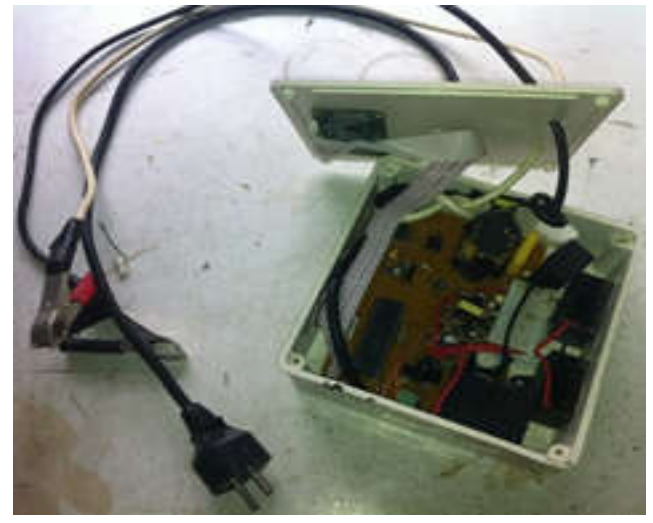

Figure 7: Internal View of the Prototype

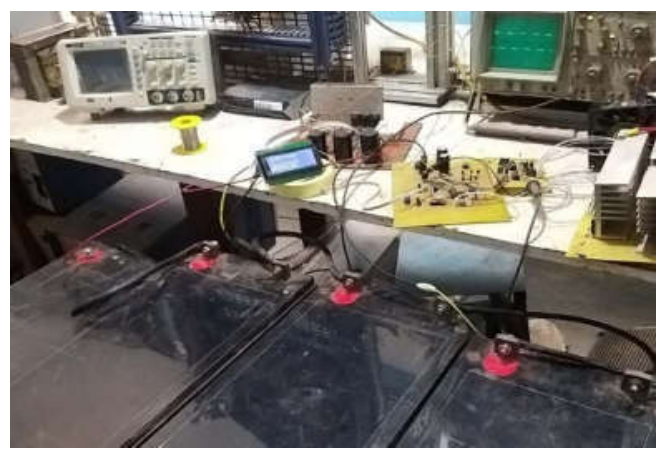

Figure 8: Experimental Setup

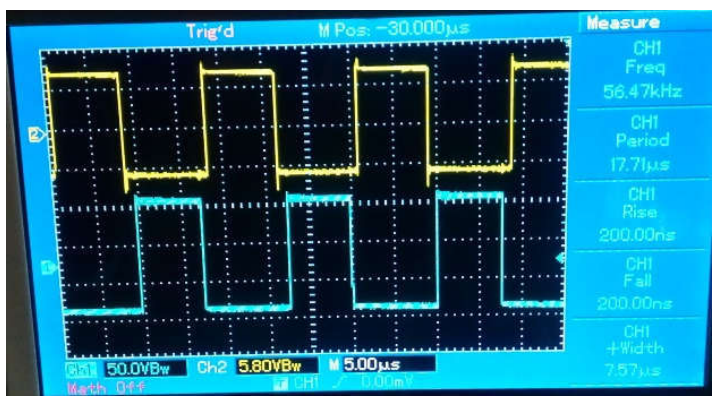

Figure 9: 50\% Duty Cycle Gate Drive Signal

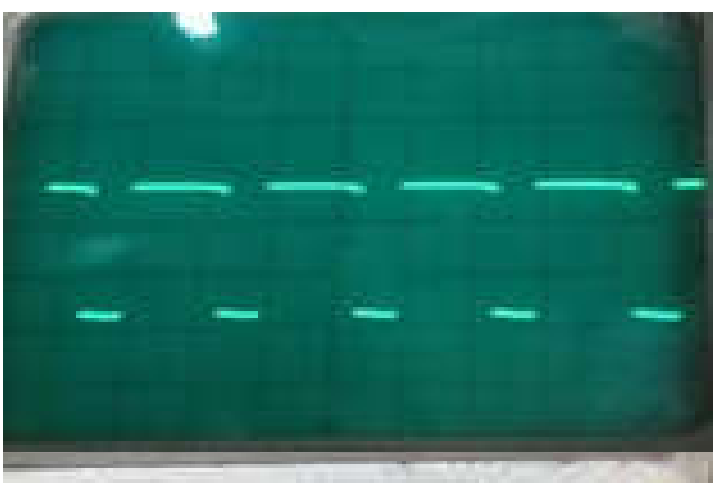

Figure 10: 75\% Duty Cycle Signals

transformer. The resultant ac voltage induced at the secondary winding of the transformer (TR1) is then rectified by the output rectifier unit to deliver DC voltage for charging the battery.

Schottky diode was chosen for rectification due to its fast reverse recovery time (switching time from turn-on to turn-off and vice versa). Connected across the rectifier diodes, is a capacitor $C_{4}$ that filters out the high ripple DC voltage. TR1 helps to isolate the load from unpleasant line disturbances associated with the input ac mains and vice visa.

\section{Results and Discussion}

The entire hardware was assembled inside a covered PVC box as shown in Figure 7. The battery charger was subjected to tests under various charging conditions and the results were in accord with objectives of the research.

Equipment used for the tests includes oscilloscope, ammeter, voltmeter, and timer. The oscilloscope was used to observe variations in duty cycle of the PWM signal which correspond to changes in charging voltage as the number of batteries connected in series is being varied. The ammeter and voltmeter were incorporated in order to measure the charging current and voltage respectively. This was necessary as a means of authenticating the values displayed by the LCD. A timer was used for taking readings at regular time intervals. The waveforms displayed on the oscilloscope in figure 9 shows that the four MOSFETs of the H-bridge switching network are turned on and off alternately in pairs at $180^{\circ}$ out of phase by the gate driver ICs based on the control signal from the microcontroller.

However, the waveforms displayed on the oscilloscope in figure 10 shows an increase in the duty cycle of the signal as the required 
charging voltage increases due to the connection of additional batteries to be charged simultaneously.

Table 1 shows the experimental results for various loads connected across the output of the battery charger. Each charging session lasted for three consecutive hours at an average of $28^{\circ} \mathrm{C}$. Initial values of the voltages and currents were noted and subsequent values were recorded at halfhour intervals. It was observed that the initial charging current is always high but depreciates with time. On the contrary, the initial battery voltage which is often low appreciates with time.

Also, it was noted that the charging voltage for 24volt battery was about twice that of a 12volt battery. Likewise, the charging voltage for 48 volt battery was approximately twice that of 24 volt battery. As the charging voltage rises, duty cycle of the PWM signal increases correspondingly indicating that output of the LLC resonant converter is being varied through pulse width modulation technique.

\section{Conclusion}

A smart battery charger using a full-bridge LLC resonant DC-DC converter has been considered and implemented. Rechargeable batteries are expensive and a frequent replacement could be unaffordable by many low income earners in developing countries. Replenishing batteries with the appropriate amount of charge will not only extend its use per charge, but will also increase the number of charge and discharge cycles during its entire working period. This implies that the whole lot of money that would be frequently spent purchasing new batteries for a replacement would be saved.

Table 1: Experimental Results for 100Ah Deep Cycle Batteries

\begin{tabular}{cccccccc}
\hline$\#$ & $\begin{array}{c}\text { Battery } \\
\text { Rated } \\
\text { Voltage } \\
\text { (Volt) }\end{array}$ & $\begin{array}{c}\text { Voltage } \\
\text { Before } \\
\text { Charging } \\
\text { (Volt) }\end{array}$ & $\begin{array}{c}\text { Charging } \\
\text { Voltage } \\
\text { (Volt) }\end{array}$ & $\begin{array}{c}\text { Initial } \\
\text { Charging } \\
\text { Current } \\
\text { (Ampere) }\end{array}$ & $\begin{array}{c}\text { Charging } \\
\text { Current After } \\
2 \text { hrs } \\
\text { (Ampere) }\end{array}$ & $\begin{array}{c}\text { Voltage } \\
\text { After } \\
\text { Charging } \\
\text { (Volt) }\end{array}$ & $\begin{array}{c}\text { No. of } \\
\text { Battery }\end{array}$ \\
1 & 6 & 5.1 & 8.5 & 7.9 & 2.3 & 6.7 & 1 \\
2 & 12 & 10.7 & 13.8 & 8.5 & 2.2 & 13.5 & 1 \\
3 & 24 & 20.9 & 28.8 & 8.7 & 2.5 & 26.4 & 2 \\
4 & 36 & 32.4 & 42.0 & 9.1 & 2.7 & 39.0 & 3 \\
5 & 48 & 42.9 & 56.0 & 9.8 & 3.1 & 54.0 & 4 \\
\hline
\end{tabular}

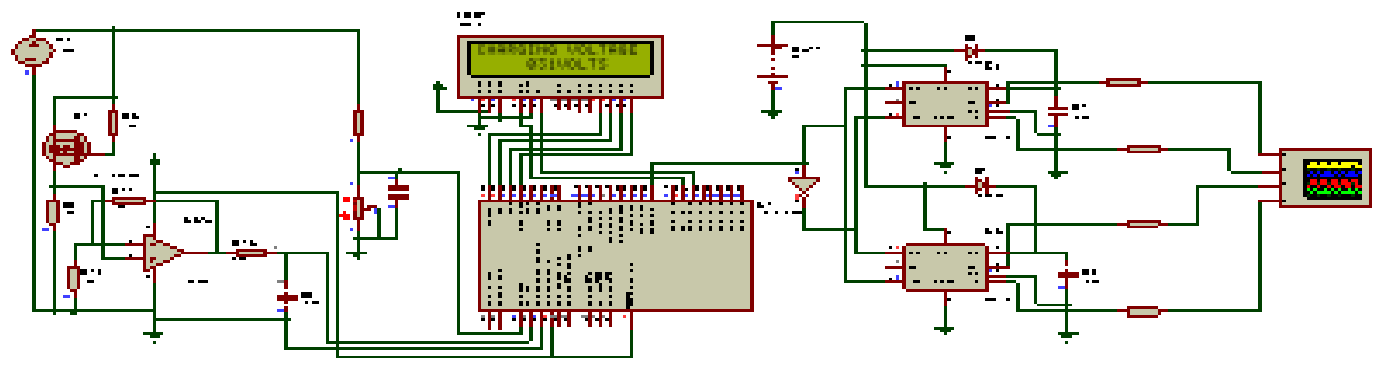

Figure 11: Control and Display Simulation Circuit 


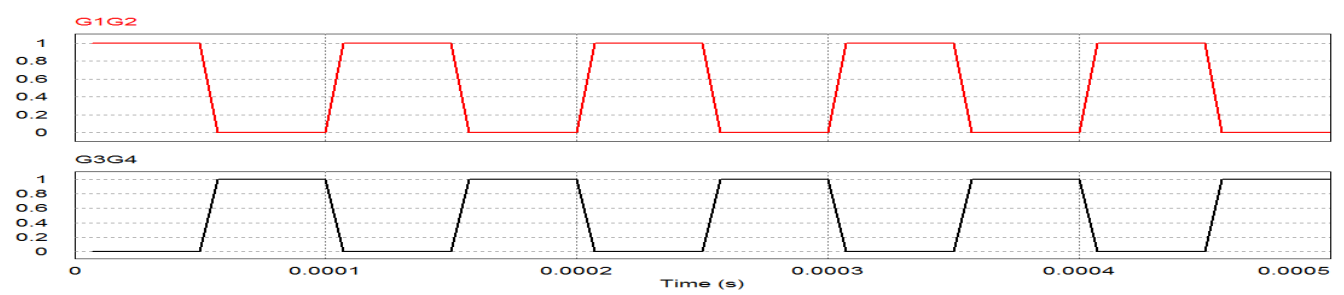

Figure 12: Simulated Gate Drive Waveform

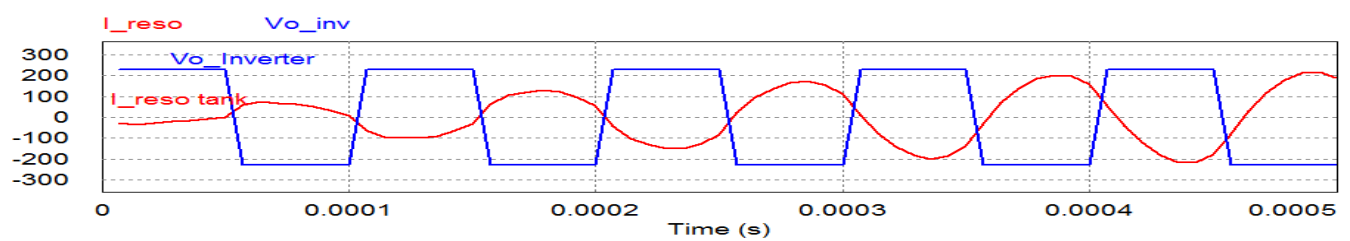

Figure 13: Simulated Resonant Inverter Output Voltage and Resonant Tank Current

This research work has produced a reliable, fast, safe, and convenient charging system as the most cost-effective means of preventing the need for repeated replacement of rechargeable battery. The developed model is expected to enhance the usage of inverter in an environment prone to a long period of power outage. It should reduce the cost of energy for charging of batteries. Also, it should address the major challenge in the deployment of electric cars. The fixedfrequency PWM method was adopted because the variable frequency control method involves more complicated control circuits. The PWM signal modifies the duty cycle of the fixed switching frequency and thereby controls the time for which the switching device stays on or off. the output of the converter at any instant is directly proportional to the switching frequency of the MOSFETs which is in turn determined by the microcontroller as it changes duty-cycle of the PWM signal.

Minimizing human interference in the operation of the system does not only make charging of batteries more comfortable and speedy but also eliminates human errors such as wrong voltage selection likely to occur in the battery charging process. Although, the numerous benefits in the use of resonant converters, particularly the LLC topology, has been discussed extensively in this paper, it is important to stress the need for enhancement of this converter. Indeed, with the zero voltage switching ability, the turn-on loss was minimized but the turn-off loss still hinders the capability of the converter to operate at a higher switching frequency. An improvement in this regard is recommended in further study.

\section{References:}

[1.] Nnanna, I. and Uzorh, A. C. "The Impact of Power Outages on Nigerian Manufacturing Sector", Proceedings of National Institute of Industrial Engineering (NIIE) Conference, Owerri, Nigeria, 2011, pp. 112-127.

[2.] Anthony, U. A., Owuama, C.E. and Timilehin F.S. "The Effect of Low Power Factor LED Lamp Invasion on the Utility Grid: A Case Study of Nigerian Market" Proceedings of IEEE PES-IAS PowerAfrica Conference, Accra, Ghana, June 27-30, 2017, pp. 413-417.

[3.] Chia-Chun Tsai "A Reduced Li-Ion Battery Charger for Portable Applications". Nineth 
International Conference on Natural Computation (ICNC); Shenyang, China, July 23-25, 2013, pp. 1718-1722.

[4.] Kularatna, N. Power Electronics Design Handbook: Low-Power Components and Applications, $1^{\text {st }}$ Edition, Newnes Boston, Oxford, Johannesburg, Melbourne, New Delhi, Singapore, 1998.

[5.] Rutto, D., Okemwa, P. and Wanami, S. "Influence of Charger-Type on Electrolyte Temperature during Charging in Eldoret Town, Kenya". International Journal of Computing and Technology, Vol. 1, Issue 8, 2014, pp. 632-639.

[6.] Abdollahi, A., Xu, H., Gopi, V., Niranjan, R., Balasingam, B., Krishna, R. and Yaakov B. "Optimal Battery Charging, Part I: Minimizing Time-to-Charge, Energy Loss, and Temperature Rise For OCV-Resistance Battery Model". Journal of Power Sources, Vol. 303, 2016, pp. 388-398.

[7.] Tahmid, H.R., Farhana, J.T., and Md. Habibur, R. "Design and Construction of a Microcontroller Based Smart Solar Charge Controller for Automatic Brightness Controlling of PV Based Street Light", Global Journal of Researches in Engineering, Vol. 17, Issue 2, 2017, pp. 13-20.

[8.] Ben, F., Ugwu N.U., Amodu F.R., and Bassey E.N. "An Improved Microcontroller Based Lead Acid Battery Charger" International Conference of Science, Engineering \& Environmental Technology (ICONSEET), Ede, Osun State, Nigeria, July 2017, pp. 265-273.

[9.] Zar Ni Tun, Aye Thin Naing, and Hla Myo Tun. "Design and Construction of Microcontroller Based Solar Battery Charger" International Journal of Scientific \& Technology Research, Vol. 5, Issue 6, 2016, pp. 117-120.

[10.] Odia, O.O., and Okpor, J. "Design and Implementation of a Microcontroller-Based Adjustable Voltage Automatic Battery Charger" Nigerian Journal of Technology (NIJOTECH), Vol. 36, No. 4, 2017, pp. 1226 $-1232$.

[11.] Namith T., Ms. Preetham S. "Design and Development of Efficient Battery Charging and Cell Balancing for Battery Management System", SASTECH Journal, Vol. 11, Issue 2, 2012, pp. 15-22.

[12.] Cheng, S.L., Hsiung, C.L., and Sin-You L. "Development of Fast Large Lead-Acid Battery Charging System Using Multi-state Strategy" International Journal on Computer,
Consumer and Control (IJ3C), Vol. 2, No. 2, 2013, pp. 56-65.

[13.] Nwosu, E.U., Olalere, N.A., Shopade, G.N. and Ogbodo, J.I. "Development of an Intelligent Battery Charging System Based on PIC16F877A Microcontroller", Proceedings of the 1st International Conference on Engineering and Environmental Sciences, Osun State, Nigeria, November 5-7, 2019, pp.45-62 